\title{
DE UN ÁREA DESÉRTICA E IMPRODUCTIVA A UN ESPACIO IDEAL PARA LA ESPECULACIÓN: LAS PERCEPCIONES SOBRE LA COSTA ATLÁNTICA BONAERENSE
}

\author{
DE UM DESERTO E ÁREA IMPRODUTIVA PARA UM \\ ESPAÇO IDEAL PARA A ESPECULAÇÃO: PERCEPÇÕES \\ SOBRE A COSTA ATLÂNTICA DE BUENOS AIRES
}

\author{
FROM A DESERT AND UNPRODUCTIVE AREA TO \\ AN IDEAL SPACE FOR SPECULATION: PERCEPTIONS \\ ABOUT ATLANTIC COAST OF BUENOS AIRES
}

\author{
Fernando Ariel Manzano - Universidad Nacional del Centro de la \\ Provincia de Buenos Aires - Buenos Aires - Argentina \\ fernandoarielmanzano@fch.unicen.edu.ar
}

Guillermo Ángel Velázquez - Universidad Nacional del Centro de la Provincia de Buenos Aires - Buenos Aires - Argentina gvelaz@fch.unicen.edu.ar

\begin{abstract}
Resumen
Este trabajo analiza el surgimiento de los balnearios más populares de la costa atlántica de Buenos Aires. El interés en su comprensión se remonta a la era colonial; por entonces la franja del territorio costero marítimo bonaerense fue adjudicada privilegiando la ocupación para defender el territorio, al margen de figuras legales y delimitaciones. Las playas estaban ubicadas al fondo de las estancias y hasta fines del siglo XIX, se las consideraba zonas improductivas. Tras los periodos de derrumbe del saladero y las crisis agropecuarias, surgió una singular "cultura de la playa". El primer ejemplo exitoso de villa balnearia fue Mar del Plata. Posteriormente este modelo se replicó en los Partidos de La Costa, Pinamar y Villa Gesell. La instalación de balneariosse realizó mediante meros trámites administrativos, produciéndose un gran desfase entre la traza "real" y la "legal". Durante la década del setenta, ante el impulso del turismo interno, se dio un marcado crecimiento de estos núcleos urbanos de la costa bonaerense. La estacionalidad de la actividad turística impuso a la población residente dificultades de empleo y de acceso a la vivienda. Además, el crecimiento urbano basado en proyectos de residencias secundarias, conllevo una alta estratificación y desorden urbano.

Palabras claves: Actividad turística, transformaciones urbanas, territorios inestables, especulación inmobiliaria.
\end{abstract}

\section{Resumo}

Este trabalho analisa 0 surgimento dos balneários mais populares da costa atlântica de Buenos Aires. 0 interesse em sua compreensão remonta à era colonial; nessa época, a orla do território costeiro de Buenos Aires foi adjudicada privilegiando a ocupação para defender o território, à margem das figuras e delimitações legais. As praias estavam localizadas no final das chácaras e, até o final do século XIX, eram consideradas zonas improdutivas. Após os períodos de colapso de terras e crises agrícolas, surge uma "cultura da praia" única. 0 primeiro exemplo de sucesso de uma villa balneária foi Mar del Plata. Mais tarde, este modelo foi replicado nas partes de La Costa, Pinamar e Villa Gesell. A instalação de balneários ocorreu por meros procedimentos administrativos, resultando em uma enorme lacuna entre o "real" e o "legal". Durante os anos 
70, antes do impulso do turismo doméstico, houve um crescimento acentuado desses centros urbanos no litoral de Buenos Aires. A sazonalidade da atividade turística impôs às populações residentes dificuldades no acesso a emprego e moradia, e o crescimento urbano baseado em projetos de residências secundárias levou a uma alta estratificação e à desordem urbana.

Palavras-chave: Atividade turística, transformações urbanas, territórios instáveis, especulação imobiliária.

\section{Abstract}

This work analyzes the emergence of the most popular spas on the Atlantic coast of Buenos Aires. The interest in its understanding goes back to the colonial era; by then the fringe of the Buenos Aires an marine coastal territory was adjudged privileging the occupation to defend the territory, to the margin of legal figures and delimitations. The beaches were located at the end of the rooms and until the end of the 19th century, they were considered unproductive zones. After the periods of landslide collapse and agricultural crises, a unique "beach culture" emerged. The first successful example of a spa town was Mar del Plata. Later this model was replicated in the Parties of La Costa, Pinamar and Villa Gesell. The installation of spas was made by mere administrative procedures, producing a large gap between the "real" and "legal" lines. In the decade of the seventies, given the boost of domestic tourism, there was a marked growth of these urban centers of the coast of Buenos Aires. The seasonality of the tourism activity imposed on the resident population difficulties in employment and access to housing, and the urban growth based on secondary residences projects led to a high stratification and urban disorder.

Keywords: Tourist activity, Urban transformations, Unstable territories, Real estate speculation.

\section{Introducción}

Partimos del supuesto que desde su génesis hasta nuestros días, el territorio Argentino se ha estructurado al compás de la demanda del mercado mundial (Santos, 2000).

Durante la etapa altoperuana ${ }^{1}$ (siglo XVI-XVII), la organización espacial respondió a la expropiación de metales preciosos del cerro de Potosí (Bolivia), con destino a las metrópolis ibéricas -en el marco de las doctrinas mercantilistas-, propiciando la fundación del virreinato del Alto Perú (Silveira 2003; Brailovsky y Foguelman, 1993). La importancia de la articulación económica, con el actual noroeste Argentino (NOA) ${ }^{2}$ como proveedor de mulas, carretas y tejidos-,ubica a esta región como la más dinámica ${ }^{3}$ (Giovannetti, 2005). Mediante una incipiente red urbana ${ }^{4}$ respondió a las necesidades del mercantilismo establecidas en las "leyes de indias" ${ }^{5}$, que además puntualizaban los criterios para la localización de las ciudades (Silveira, 1999, 2003) ${ }^{6}$.

Hacia la postrimería del siglo XVIII, se produce la decadencia económica española , contribuyendo a la misma la extenuación de la mina de plata de Potosí, simultáneamente surge Gran Bretaña como nueva potencia del naciente capitalismo industrial y con fuertes ambiciones expansionistas (Cárcano, 1972). La nueva organización del comercio 
mundial impuso cambios en la distribución espacial del territorio argentino $^{7}$, que se adecuo a la estructura de nueva demanda externa demanda mundial de cueros y carnes saladas- ${ }^{8}$.

El avance de la revolución industrial europea fue acompañada de una nueva racionalidad comercial basada en el liberalismo - dejando atrás al mercantilismo-, sucesivamente se plasmara la modernidad europeizada en El Litoral y fundamentalmente en Buenos Aires ${ }^{9}$, representando un nuevo periodo (Hora, 2014), - denominado "argentina criolla"10-.

Luego de este rápido racconto sobre la estructuración del territorio Argentino hasta el siglo XVIII. En los apartados siguientes se procedió haciendo usufructo de lo aportado por los historiadores y las principales líneas de investigación, a examinar las configuraciones en la distribución y ocupación del suelo, que acompañaron los procesos de racionalización económica y de cambios en el comercio mundial. Luegos e ingresara a la parte central del estudio, que tiene por objetivo caracterizar mediante factores históricos, ambientales, sociales y económicos la formación de los asentamientos turísticos de la Costa Atlántica Bonaerense, y el pasaje de estas zonas con nulo interés económico y percepción desfavorable en el pasado, y tiempo después representaran espacios urbanos valorizados muy por encima de las zonas linderas, que no fueron perturbadas por un tipo de urbanización particular (la creación de balnearios).

\section{Buenos Aires como nuevo centro gravedad del país}

Los “trabajos clásicos” expresan críticas respecto a la conquista Española basada en la ocupación de amplios territorios (Avellaneda, 1915), esa metodología de repartición de tierra conllevo a un problema histórico, estableciendo la estancia ${ }^{11}$ como unidad de producción.

Débilmente defendido por los precarios fuertes ${ }^{12}$ que se levantaron a mediados del siglo XVIII (Banzato, 2009), el puerto de Buenos Aires se presentaba estratégico para los nuevos circuitos mercantiles. Así Buenos Aires se transformó en la ciudad principal de la economía colonial (Silveira, 2003; Moreno, Mateo, 1997), el centro territorial se desplazó desde el Noroeste hacia el Litoral. Se dio inicio a la expansión de la frontera bonaerense, conforme se incorporaban nuevas apropiaciones de tierra, la Corona Española ${ }^{13}$ demandaba la creación de un fortín, como política defensiva ante las sociedades nativas (Canedo, 2006). Sin embargo, 
los ejidos en la campaña bonaerense se alejaron de lo propuesto por el proyecto colonial ${ }^{14}$.

Los hombres de Mayo ${ }^{15-16-17}$ tuvieron plena conciencia de la necesidad de constituir una clase de medianos o pequeños propietarios rurales, pero se enfrentaban a los hacendados, en especial los de Buenos Aires, que tenían grandes cantidades de tierras e influencia en el gobierno. De esta manera las aspiraciones de los hombres de la Revolución se verán frustradas, el cumplimiento de sus decretos ${ }^{18}$ no estaba en sintonía con la clase terrateniente latifundista (Raimundo, 1981).

Entre 1829 y 1852 se destaca en el terreno político la influencia de Juan Manuel de Rosas ${ }^{19}$, no sólo en la Provincia de Buenos Aires, su figura tuvo proyección nacional. Las fuerzas políticas en esta época corresponden son dos sectores de la clase dominante - emergieron tras la lucha interna en la legislatura de Buenos Aires, los unitarios y los federales.

Los primeros expresaban a los grandes comerciantes porteños y del interior, eran partidarios del librecambio y defensores de la política del puerto único, mientras del lado del partido federal existió una mayor heterogeneidad de ideas - principalmente, el grupo a favor de la Confederación, y el federalismo bonaerenses con interés en el puerto y la aduana -. Cabe destacar, que ambos partidos diferían mucho más en la forma que en el contenido ${ }^{20}$. Rosas adoptó la denominación federal para imponer un modelo porteño, evitando la resistencia de los federalismos provinciales, utilizo el disciplinamiento mediante el terror contra el disenso.

En 1829 la Legislatura lo eligió gobernador ${ }^{21}$, su primer gobierno entre 1829-32, se destacó por renovar las leyes suprimidas en el golpe unitario por la cual se ganó el título de "Restaurador de las leyes".

Rosas $^{22}$ resultará elegido nuevamente gobernador en el año 1835 con poderes discrecionales, se destacan la promulgación de la ley de Aduana $^{23}$ (Infesta y Valencia, 1987) y en 1840 decretó de embargo ${ }^{24}$ de los "bienes muebles e inmuebles, derechos y acciones de cualquier clase en la ciudad y campaña” de los “unitarios” (Gelman, Schroeder, 2003). De esta manera la rivalidad económica, se tradujo en rivalidad política ${ }^{25-26-27}$

Entre 1845 y 1850 se produce un bloqueo de todos los puertos argentinos y uruguayos por parte de Francia e Inglaterra28. Los acuerdos alcanzados con las potencias dan cuenta de la extensa y densa relación entre la oligarquía latifundista y sus socios ingleses y franceses. 
El dominio exclusivo de los ríos despertó la oposición de las provincias del Litoral, tuvo como desenlace el derrocamiento de Rosas ${ }^{29-30}$.

En el marco de las reformas liberales ${ }^{31}$, se sancionó en 1858 la ley de venta de terrenos ejidales para los pueblos de campaña de Buenos Aires, que se proponía de quebrar el pasado rosista.

Se transitó un periodo de gran desbarajuste normativo hasta la sanción de la Ley General de Ejidos de 1870, mediante la cual se establecían los factores para la localización de la fundación de los nuevos pueblos de campaña.

Existía una percepción desfavorable sobre el poblamiento de las costas marítimas de la provincia de Buenos Aires, considerando esta dilatada franja del territorio ausente de atractivo tanto para los agricultores, como para los ganaderos.

La percepción negativa de la zona marítima de Buenos Aires (hacia fines del siglo XIX)

Para la clase gobernante las áreas costeras eran visualizadas entre las zonas improductivas del país, no merecerían salir de la categoría de desierto (Mantobani, 1997).

Conforme al primer censo Nacional realizado en el año 1869, Buenos Aires se presentó a los fines de la apreciación estadística dividida en tres zonas o agrupaciones (Norte, Centro y Sud). La parte Sud era la región más extensa, y entrañaba el 27,7\% de la población de la provincia, distribuida en 35 secciones.

Sólo el 1,5\% de la población total de la Provincia en el año 1869 se encontraba en los partidos que limitan al Este con el Océano Atlántico y que tendrán como actividad principal al turismo de playa (Ajó, Tuyú, Mar Chiquita y Necochea). En la racionalidad económica de fines del siglo XIX, no existía ningún interés sobre las costas bonaerenses -ni respecto de la utilidad de las playas. Ver Cuadro 1. 
ISSN: 1984-8501 Bol. Goia. Geogr. (Online). Goiânia, v. 38, n. 2, p. 224-250, maio/ ago. 2018

\begin{tabular}{|c|c|c|c|c|c|c|c|c|c|c|}
\hline \multirow{2}{*}{ Secciones } & \multirow{2}{*}{ Población } & \multirow{2}{*}{$\%$} & \multicolumn{2}{|c|}{ Argentinos } & \multicolumn{2}{|c|}{ Extranjeros } & \multicolumn{2}{|c|}{ Argentinos (\%) } & \multicolumn{2}{|c|}{ Extranjeros (\%) } \\
\hline & & & Varones & Mujeres & Varones & Mujeres & Varones & Mujeres & Varones & Mujeres \\
\hline Buenos Aires & 495.107 & & 165.919 & 177.947 & 108.954 & 42.287 & 33,5 & 35,9 & 22,0 & 8,5 \\
\hline Agrupació Sud & 137.306 & 27,7 & 57.056 & 52.558 & 21.404 & 6.288 & 41,6 & 38,3 & 15,6 & 4,6 \\
\hline Sub Total & & 100,0 & & & & & & & & \\
\hline Barracas al Sud & 8.003 & 5,9 & 1.784 & 2.160 & 2.777 & 1.282 & 22,3 & 27,0 & 34,7 & 16,0 \\
\hline $\mathrm{LaPaz}$ & 1.723 & 1,3 & 541 & 534 & 513 & 135 & 31,4 & 31,0 & 29,8 & 7,8 \\
\hline Quilmes & 6.809 & 5,0 & 1.983 & 2.314 & 1.920 & 592 & 29,1 & 34,0 & 28,2 & 8,7 \\
\hline San Vicente & 4.249 & 3,1 & 1.508 & 1.699 & 812 & 230 & 35,5 & 40,0 & 19,1 & 5,4 \\
\hline Ensenada & 4.440 & 3,3 & 1.784 & 1.868 & 594 & 194 & 40,2 & 42,1 & 13,4 & 4,4 \\
\hline Cañuelas & 4.749 & 3,5 & 1.899 & 2.080 & 606 & 164 & 40,0 & 43,8 & 12,8 & 3,5 \\
\hline Magdalena & 5.626 & 4,1 & 2.446 & 2.391 & 566 & 223 & 43,5 & 42,5 & 10,1 & 4,0 \\
\hline Rivadavia & 2.253 & 1,7 & 942 & 904 & 315 & 92 & 41,8 & 40,1 & 14,0 & 4,1 \\
\hline Ranchos & 5.616 & 4,1 & 2.235 & 2.355 & 792 & 234 & 39,8 & 41,9 & 14,1 & 4,2 \\
\hline Monte & 4.706 & 3,5 & 1.745 & 1.964 & 773 & 224 & 37,1 & 41,7 & 16,4 & 4,8 \\
\hline Chascomús y Biedma & 9.637 & 7,1 & 3.503 & 3.524 & 2.007 & 603 & 36,3 & 36,6 & 20,8 & 6,3 \\
\hline Las Flores & 7.252 & 5,3 & 3.036 & 2.970 & 986 & 260 & 41,9 & 41,0 & 13,6 & 3,6 \\
\hline Saladillo & 7.341 & 5,4 & 3.505 & 2.821 & 838 & 177 & 47,7 & 38,4 & 11,4 & 2,4 \\
\hline Pila & 2.728 & 2,0 & 1.196 & 1.019 & 401 & 112 & 43,8 & 37,4 & 14,7 & 4,1 \\
\hline Castelli & 1.655 & 1,2 & 656 & 636 & 275 & 88 & 39,6 & 38,4 & 16,6 & 5,3 \\
\hline Dolores & 7.203 & 5,3 & 2.546 & 3.338 & 927 & 392 & 35,3 & 46,3 & 12,9 & 5,4 \\
\hline Tordillo & 705 & 0,5 & 385 & 285 & 33 & 2 & 54,6 & 40,4 & 4,7 & 0,3 \\
\hline Vecino & 2.516 & 1,8 & 1.142 & 988 & 307 & 79 & 45,4 & 39,3 & 12,2 & 3,1 \\
\hline Rauch & 3.591 & 2,6 & 1.734 & 1.450 & 349 & 58 & 48,3 & 40,4 & 9,7 & 1,6 \\
\hline Arenales & 3.253 & 2,4 & 1.573 & 1.244 & 354 & 82 & 48,4 & 38,2 & 10,9 & 2,5 \\
\hline Ayacucho & 2.993 & 2,2 & 1.375 & 1.146 & 415 & 57 & 45,9 & 38,3 & 13,9 & 1,9 \\
\hline Tapalqué & 2.394 & 1,8 & 1.186 & 955 & 204 & 49 & 49,5 & 39,9 & 8,5 & 2,0 \\
\hline Ajó & 3.381 & 2,5 & 1.588 & 1.349 & 360 & 84 & 47,0 & 39,9 & 10,6 & 2,5 \\
\hline Monsalvo & 3.810 & 2,8 & 2.011 & 1.362 & 348 & 89 & 52,8 & 35,7 & 9,1 & 2,3 \\
\hline Tuyú & 673 & 0,5 & 343 & 268 & 56 & 6 & 51,0 & 39,8 & 8,3 & 0,9 \\
\hline Azul & 7.209 & 5,3 & 3.005 & 2.858 & 1.072 & 274 & 41,7 & 39,6 & 14,9 & 3,8 \\
\hline Mar Chiquita & 2.289 & 1,7 & 1.054 & 909 & 271 & 55 & 46,0 & 39,7 & 11,8 & 2,4 \\
\hline Tandil & 4.870 & 3,6 & 2.102 & 2.001 & 578 & 189 & 43,2 & 41,1 & 11,9 & 3,9 \\
\hline Balcarce & 4.198 & 3,1 & 2.090 & 1.564 & 459 & 85 & 49,8 & 37,3 & 10,9 & 2,0 \\
\hline Loberia & 2.901 & 2,1 & 1.512 & 1.103 & 251 & 35 & 52,1 & 38,0 & 8,7 & 1,2 \\
\hline Necochea & 1.129 & 0,8 & 729 & 310 & 87 & 3 & 64,6 & 27,5 & 7,7 & 0,3 \\
\hline Juárez & 1.610 & 1,2 & 962 & 496 & 145 & 7 & 59,8 & 30,8 & 9,0 & 0,4 \\
\hline Tres Arroyos & 550 & 0,4 & 404 & 103 & 39 & 4 & 73,5 & 18,7 & 7,1 & 0,7 \\
\hline Bahia Blanca & 1.472 & 1,1 & 613 & 574 & 236 & 49 & 41,6 & 39,0 & 16,0 & 3,3 \\
\hline Patagones & 2.567 & 1,9 & 1.114 & 938 & 439 & 76 & 43,4 & 36,5 & 17,1 & 3,0 \\
\hline
\end{tabular}

Cuadro 1 - Población absoluta y relativa, por nacionalidad y sexo. Agrupación Sud. Año 1869

Fuente: Elaboración personal sobre la base de información de la Dirección Nacional de Estadística. Año 1869.

La parte Sud de la provincia de Buenos Aires presentaba sobre el Atlántico tres puertos, Ajó, Bahía Blanca y Patagones. El puerto de Ajó tuvo una alta actividad tras el bloqueo francés ${ }^{32}$ al puerto de Buenos Aires -como hemos mencionado-, logrando el rango de puerto nacional en 1859. En 1864 se dispuso la fundación del pueblo de General Lavalle sobre la margen derecha de la ría de Ajó. Estrechamente vinculadas con el puerto se asentaron en la zona las primeras industrias saladeriles (Varela, 1997). El auge de la actividad saladeril ${ }^{33}$ generó que el puerto de Lavalle fuera, en 1880, el tercero en importancia del país -después de los de Buenos Aires y Rosario -, (Bertolotti, Gil de Muro, 1991). La zona costera formaba 
parte de las estancias agropecuarias cuyos fondos llegaban hasta la playa (Verón, 2006), estas habían sido confiscadas por Rosas, y tras su caída fueron adjudicadas a nuevos propietarios.

El Poder Ejecutivo impulsó la creación de doce pueblos en 1882, uno de estos a fundarse en el partido del Tuyú ${ }^{34-35}$ con el nombre de “Dorrego" (Provincia de Buenos Aires, 1882). No existió en el imaginario de la época, otro tipo de modelo de urbanización relacionado con las playas marítimas que no estuviera ligado a la existencia de un puerto o algún tipo de producción primaria.

En el contexto de planificación productiva del siglo XIX, el proyecto agroexportador implicaba una mirada permanente hacia el río de la Plata y sus afluentes. Las costas marítimas eran consideradas estériles, improductivas e inadecuadas para ser habitadas, un "terreno inútil compuesto por puros médanos" (Pisani, 1997), en donde las estancias cimentaban la riqueza nacional que iba a morir al mar. En contraposición, a fines del siglo XX el valor de esos terrenos superará ampliamente al de las zonas agrícolas.

El área denominada socioecosistema Litoral Norte de la provincia de Buenos Aires (Verón y Barragán Muñoz, 2015), en el centro este de la provincia, correspondía en el año 1914 a los partidos de Juan Madariaga ${ }^{36}$ (luego se desprenderán los emplazamientos de Pinamar, Villa Gesell y General Lavalle). ${ }^{37}$ Su uso estuvo ligado a la actividad agropecuaria en el marco de la Argentina agroexportadora: la cría de ganado ovino y sus derivados (lana y grasa) y de ganado bovino (Vervoorst, 1967; Randle, 1981; Ghersa y León, 2001), quedando el área costera relegada y sin uso alguno.

En 1880 se produjo el derrumbe de la industria saladeril ante el advenimiento de los frigoríficos ${ }^{38}$ (Varela, 1997), el ritmo de crecimiento de la población rural en General Lavalle (utilizando como medida la tasa de crecimiento anual medio, en adelante TCMA), decreció en-30,1 personas cada 1.000 habitantes y la urbana $-9,1 \%$ durante el periodo $1895-1914^{39}$ (Ver Cuadro 2).

Se produjo un aumento de la ganadería bovina en ambos partidos en detrimento de la ovina y la equina. En menor medida, en el área de General Madariaga se diversificó la producción agropecuaria mostrando una incipiente producción agrícola cereal era que, si bien ganó terreno hasta 1937, luego fue suplantada por la ganadería intensiva ${ }^{40}$ (Ghersa y 
León, 2001), presentando un aumento de la población rural de 17,7\%o entre los años 1895 y 1914 -muy inferior al crecimiento total que fue de 38,8\%o-.

\begin{tabular}{|c|c|c|c|c|c|c|c|c|c|}
\hline \multirow{2}{*}{ Partido } & \multirow{2}{*}{\begin{tabular}{|c|} 
Tipo de \\
producció
\end{tabular}} & \multicolumn{3}{|c|}{ Cabezas de ganados por año } & \multirow{2}{*}{ Partido } & \multirow{2}{*}{ Area } & \multicolumn{3}{|c|}{ Población } \\
\hline & & 1895 & 1914 & 1947 & & & 1970 & 2001 & 2010 \\
\hline \multirow{3}{*}{$\begin{array}{l}\text { General Lavalle } \\
\text { (1) }\end{array}$} & Bovina & 50.113 & 65.286 & 123.065 & \multirow{3}{*}{ General Lavalle } & Total & 14.639 & 3.063 & 3.700 \\
\hline & Ovina & 513.834 & 292.856 & 177.561 & & Urbana & 10.226 & 162 & - \\
\hline & Equina & 18.012 & 22.227 & 18.017 & & Rural & 4.413 & 2.901 & 3.700 \\
\hline \multirow{3}{*}{$\begin{array}{c}\text { General } \\
\text { Madariaga }\end{array}$} & Bovina & 97.049 & 97.083 & 153.045 & \multirow{3}{*}{$\begin{array}{c}\text { General } \\
\text { Madariaga }\end{array}$} & Total & 20.567 & 18.286 & 19.747 \\
\hline & Ovina & 450.564 & 342.795 & 289.297 & & Urbana & 15.621 & 16.763 & 18.089 \\
\hline & Equina & 18.286 & 12.641 & 8.892 & & Rural & 4.946 & 1.523 & 1.658 \\
\hline & & & & & \multirow{3}{*}{$\begin{array}{c}\text { General } \\
\text { Pueyrredón }\end{array}$} & Total & 317.444 & 564.056 & 618.989 \\
\hline \multirow{2}{*}{ Partido } & \multirow{2}{*}{ Area } & & oblación & & & Urbana & 305.672 & 551.530 & 607.738 \\
\hline & & 1895 & 1914 & 1947 & & Rural & 11.772 & 12.526 & 11.251 \\
\hline \multirow{3}{*}{ General Lavalle } & Total & 5.938 & 3.931 & 5.666 & \multirow{3}{*}{ La Costa ${ }^{(3)}$} & Total & - & 60.483 & 69.633 \\
\hline & Urbana & 2.090 & 1.758 & - & & Urbana & - & 60.149 & 69.451 \\
\hline & Rural & 3.848 & 2.173 & 5.666 & & Rural & - & 334 & 182 \\
\hline \multirow{3}{*}{$\begin{array}{c}\text { General } \\
\text { Madariaga }\end{array}$} & Total & 3.201 & 6.694 & 12.252 & \multirow{3}{*}{ Pinamar ${ }^{(4)}$} & Total & - & 20.666 & 25.728 \\
\hline & Urbana & \begin{tabular}{l|l}
- \\
\end{tabular} & 2.213 & 7.073 & & Urbana & - & 20.592 & 25.397 \\
\hline & Rural & 3.201 & 4.481 & 5.179 & & Rural & - & 74 & 331 \\
\hline \multirow{3}{*}{$\begin{array}{c}\text { General } \\
\text { Pueyrredón }\end{array}$} & Total & 8.175 & 32.940 & 123.811 & \multirow{3}{*}{ Villa Gesell $^{(5)}$} & Total & - & 24.282 & 31.730 \\
\hline & Urbana & 5.187 & 25.090 & 114.729 & & Urbana & - & 23.257 & 29.593 \\
\hline & Rural & 2.988 & 7.850 & 9.082 & & Rural & - & 1.025 & 2.137 \\
\hline
\end{tabular}

Cuadro 2 - Población según área de residencia y tipo de producción ganadera. Partidos seleccionados General Madariaga y General Pueyrredon. Años 1895, 1914, 1947, 1970, 2001 y 2010.

Nota: (1) En 1881 General Lavalle toma el estatus de partido. Incluye hasta 1970 al partido de La Costa, (2) Hasta el año 1910 denominado partido de Tuyu, incluye hasta 1970 los partidos de Pinamar y Villa Gesell; (3) Hasta 1970 incluido en el partido de General Lavalle; (4) Hasta 1970 incluido en el partido de General Madariaga y (5) Hasta 1970 incluido en el partido de General Madariaga

Fuente: Elaboración personal sobre la base de los censos de 1895, 1914, 1947, 1970, 2001 y 2010.

El surgimiento del turismo en Argentina, la originalidad de Mar del Plata

Bajo el nombre de Mar del Plata ${ }^{41}$ se inició un proceso de transición urbana ${ }^{42}$ hacia un pueblo balneario ${ }^{43}$, vinculado a varios factores: la promesa de llegada del ferrocarril, la crisis de las actividades agropecuarias y del saladero, la aparición de una singular "cultura de la playa” (Mantobani, p. 7, 1997), y el apoyo político ${ }^{44}$ y financiero para urbanizar el territorio (Groussac, 1904). 
De esta manera Mar del Plata pasó de ser un paraje que ni siquiera figuraba en los mapas, a ser uno de los proyectos de modernización más importantes de la Generación del Ochenta ${ }^{45}$ (Cova, 1980).

En 1879 se creó el Partido de General Pueyrredón en cuyo interior se encuentra Mar del Plata, como un desprendimiento del Partido de Balcarce (creado en 1865).

En el Cuadro 2 se aprecia que la TCMA más elevada se dio en el periodo 1895-1914 de 73,3 cada 1.000 personas, y un tasa de 40,1\%o en el intervalo 1914-1947 (mientras el aumento poblacional fue de 11,1\%o y 18,3\%o en General Lavalley General Madariaga, respectivamente). Durante el periodo 1947-1970, el crecimiento de la población urbana en los tres partidos mencionados presento valores similares a la provincia de Buenos Aires (inferiores al total nacional).

General Lavalle toma el estatus de Partido en 1881, incorporando en su interior al Partido "Rincón de Ajó", la TCMA del periodo 18952010 arrojó una valor de $-4,1 \%$ o, se destaca un continuo descenso de su población rural hasta 1970 (en 1985 el 64,8\% de la población era rural, y en 1970 solo el 30,1\%), mientras que en los dos últimos censos se produjo un cuenta cambio en la tendencia, encontrándose el total de población en el área rural (94,7\% y 100,0\%, en los años 2001 y 2010, respectivamente). Esto no ocurrió en el Partido de General Madariaga que siguió un patrón urbanización similar al del partido de General Pueyrredón, aunque de menor intensidad (Ver Cuadro 2).

La estructura de edad en los orígenes del partido de General Pueyrredón presentó alta participación de jóvenes de nacionalidad argentina -casi el 70\%-, en tanto la población extranjera residente se destacó por su concentración en edad de trabajar, en claro contraste con el Partido de Lavalle en donde la inmigración internacional representaba apenas $21,3 \%$ en 1895, caracterizándose por estar relativamente envejecida. Ver Figura 1. 

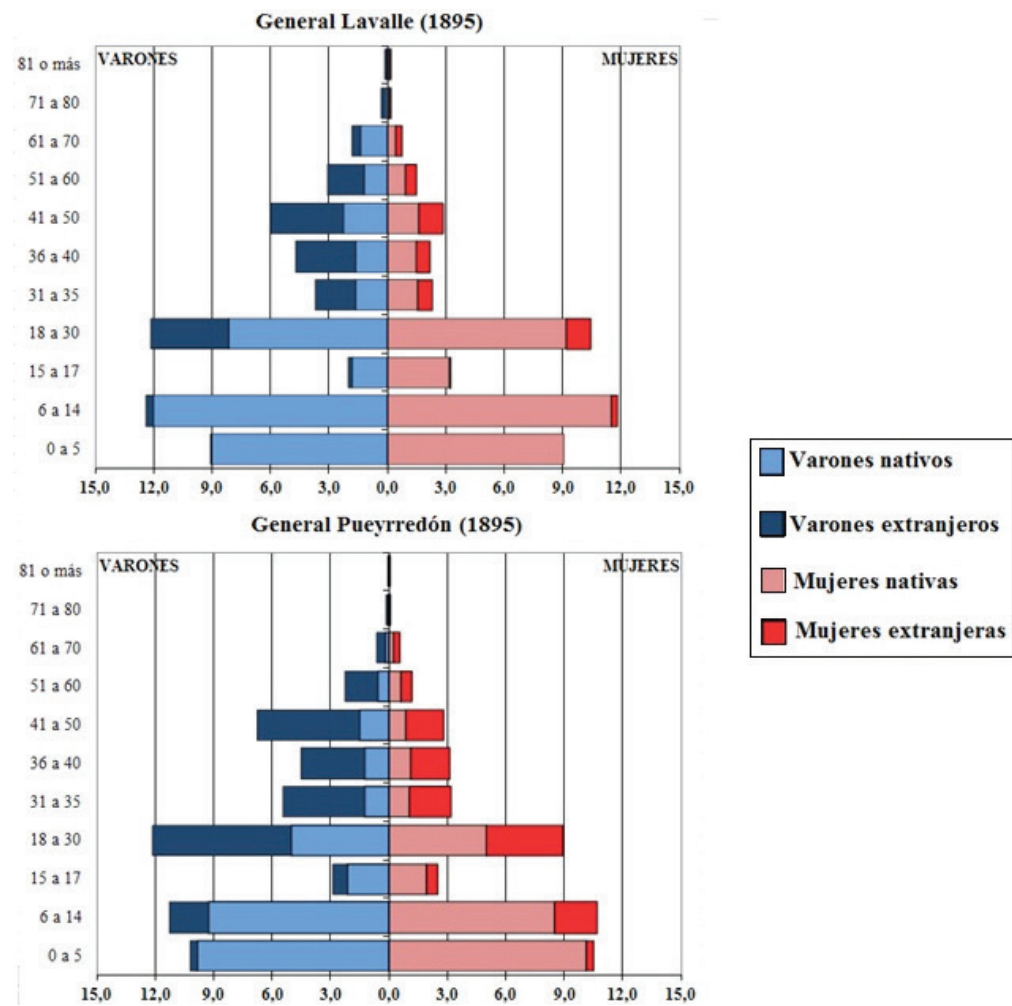

Figura 1 - Población nativa y extranjera según edad y sexo. Partidos seleccionados de la Regiones Central y Sud de la provincia de Buenos Aires. Año 1895.

Fuente: Elaboración personal sobre la base de información de la Dirección Nacional de Estadística. Año 1895.

Como fue mencionado, el ecosistema costero no estaba valorizado económicamente debido al auge del modelo agroexportador, que concentraba su atención tierra adentro, encontrándose esta zona bajo la propiedad de estancieros. Hasta principios de siglo XX:“[...] La racionalidad productiva basada en una primitiva economía ganadera desvalorizó las potencialidades del área litoral que fueron los ámbitos más marginados [...]” (Villar, 2003, p. 14).

Se produjo un cambio respecto de la percepción de las playas sobre el océano Atlántico y su incorporación al sistema económico - asimilado 
primeramente por la clase alta- ${ }^{46}$, mostró la capacidad de este recurso recreativo ${ }^{47}$ para animar la economía urbana ${ }^{48}$.

El éxito de Mar del Plata como villa balnearia ${ }^{49}$ y los grandes progresos que experimentó a partir de la llegada del ferrocarril en conjunto con las condiciones económicas del país, propicias para la especulación inmobiliaria, motivaron la rápida difusión del modelo. El "veraneo" de toda la familia ${ }^{50}$ irá convirtiéndo se en una actividad social indispensable para los sectores más acaudalados de la sociedad ${ }^{51}$.

El modelo de urbanización de la costa atlántica (las fundaciones), inspirado en Mar del Plata

La costa atlántica permaneció sin poblar ${ }^{52}$ desde fines del siglo XIX, pero el surgimiento de las playas como atracción turística (Mantobani, 1997), se buscó valorizar estas tierras que poseían excelentes condiciones de sitio y posición (en tanto playas marítimas más próximas a la Metrópoli Nacional), mediante la instalación de pueblos balnearios. La fundación de los mismos consistió en meros trámites administrativos aprobados según Ley de Fundación de Pueblos vigente en la provincia de Buenos Aires desde 1913 (N. 3487 y sus decretos reglamentarios de 1927 y 1929) (33 $^{53}$ (Bertoncello, 1992).

Existió un gran desfasaje entre la traza "real" y la "legal", agravado por la magnitud de las subdivisiones. El predominio del damero cruzado a lo sumo por algunas diagonales, resultó contradictorio con la función de área de esparcimiento y recreación, lo que se explica por el carácter especulativo de la urbanización, más preocupada por la simplicidad de la división catastral y la rapidez del replanteo ${ }^{54}$

La apertura de los balnearios a los sectores urbanos medios ${ }^{55}$ estuvo vinculada al llamado "turismo social" que se iniciócon el primer gobierno peronista a mediados de 1940. Ordoqui y Hernández (2009), calificaa la segunda etapa del turismo de sol y playa como Turismo Masivo. De esta manera, a partir de los años sesenta ${ }^{56}$ comienza a cobrar mayor importancia el hábito de hacer turismo ${ }^{57}$ entre capas cada vez más amplias de la población (Schluter, 1983, 1985).

En el Cuadro 2 se aprecia que los partidos de General Lavalle y Madariaga tuvieron un decrecimiento poblacional entre los años 19702001, siendo de -50,5\% y -3,8\%o, por el contrario General Pueyrredón 
presento un crecimiento de $18,5 \%$ on dicho periodo (superando el valor de la provincia de Buenos Aires 14,7\%o y del total país 14,2\%o).

El patrón de urbanización de las zonas costeras difirió del realizado en las tierras altas dentro de la misma ecoregión. Su evolución fue dependiente del turismo interno y, por tanto, de los cambios macroeconómicos. Durante la década del setenta aproximadamente, se dio un marcado crecimiento de estos núcleos urbanos ${ }^{58}$ de la costa bonaerense ante la demandas del turismo interno, imponiendo mayor presión sobre estos ambientes costeros ${ }^{59}$ (Morello, 1983). Para el período 1970-1980 los municipios urbanos de Pinamar y Villa Gesell aportaron significativamente al crecimiento de viviendas del partido de Madariaga que alcanzo el 180,7\%, lo mismo sucedió al interior del Partido de Lavalle, donde se registró un aumento del parque habitacional de 183,5\%, siendo de 99,0\% el aporte del municipio urbano de La Costa (ver Cuadro 3), por tantoun incremento notablemente superior al poblacional.

Utilizando el indicador "cantidad de habitantes por cada vivienda", los nuevos municipios urbanos presentan un valor notablemente inferior a los partidos mencionados. Mientras que si se escoge el indicador "cantidad de habitantes por cada vivienda ocupada”, no se presentan diferencias significativas.

\begin{tabular}{|c|c|c|c|c|c|c|c|c|c|c|}
\hline \multirow{2}{*}{ Jurisdicciones } & \multicolumn{4}{|c|}{ Total de Viviendas particulares (a) } & \multicolumn{3}{|c|}{ Población en viviendas particulares (b) } & \multicolumn{3}{|c|}{ Viviendas particulares Ocupadas (c) } \\
\hline & 1970 & 1980 & 2001 & 2010 & \begin{tabular}{|l|l}
1980 \\
\end{tabular} & 2001 & 2010 & 1980 & 2001 & 2010 \\
\hline Buenos Aires & 2.627 .106 & 3.367 .506 & 4.709 .893 & 5.377 .786 & 10.728 .931 & 13.708 .190 & 15.482 .596 & 2.865 .973 & 4.709 .893 & 5.377 .786 \\
\hline General Pueyrredón & 139.014 & 204.560 & 285.599 & 307.404 & \begin{tabular}{|l|}
422.546 \\
\end{tabular} & 553.667 & 606.213 & 122.956 & 285.599 & 307.404 \\
\hline General Madariaga & 10.212 & 4.980 & 6.628 & 7.636 & 15.386 & 18.169 & 19.611 & 4.180 & 6.628 & 7.636 \\
\hline General Lavalle & 14.541 & 396 & 1.328 & 1.659 & 1.199 & 3.015 & 3.650 & 315 & 1.328 & 1.659 \\
\hline La Costa & - & 40.831 & 87.162 & 97.857 & 25.286 & 59.608 & 68.652 & 7.267 & 87.162 & 97.857 \\
\hline Pinamar & - & 9.105 & 19.019 & 24.369 & 5.284 & 19.473 & 24.810 & 1.583 & 19.019 & 24.369 \\
\hline Villa Gesell & - & 14.585 & 23.146 & 30.793 & 11.305 & 23.380 & 31.007 & 3.259 & 23.146 & 30.793 \\
\hline \multirow{2}{*}{\multicolumn{5}{|c|}{ Jurisdicciones }} & \multicolumn{3}{|c|}{ (b) / (a) } & \multicolumn{3}{|c|}{ (b) $/$ (c) } \\
\hline & & & & & 1980 & 2001 & 2010 & 1980 & 2001 & 2010 \\
\hline Buenos Aires & & & & & 3,2 & 2,9 & 2,9 & 3,7 & 3,6 & 3,5 \\
\hline General Pueyrredón & & & & & 2,1 & 1,9 & 2,0 & 3,4 & 3,2 & 3,0 \\
\hline General Madariaga & & & & & 3,1 & 2,7 & 2,6 & 3,7 & 3,4 & 3,2 \\
\hline General Lavalle & & & & & 3,0 & 2,3 & 2,2 & 3,8 & 3,5 & 3,2 \\
\hline La Costa & & & & & 0,6 & 0,7 & 0,7 & 3,5 & 3,3 & 3,0 \\
\hline Pinamar & & & & & 0,6 & 1,0 & 1,0 & 3,3 & 3,4 & 3,2 \\
\hline Villa Gesell & & & & & 0,8 & 1,0 & 1,0 & 3,5 & 3,3 & 3,1 \\
\hline
\end{tabular}

Cuadro 3 - Viviendas particulares según ocupación y población censada en ellas. Partidos seleccionados de la Regiones Central y Sud de la provincia de Buenos Aires. Años: 1970,1980, 2001 y 2010.

Nota:(c) En la vivienda se encontraban las personas presentes 
El modelo de desarrollo de los Balnearios se base en el turismo como actividad principal, caracteriza por su estacional (dos o tres meses por año), y concentración económicaen el espacio. Entre las consecuencias negativas de la estacionalidad, cabe destacar la necesidad de una infraestructura y equipamiento ser muy grande -que permanece ocioso la mayor parte del año-, periodos de desempleo en la población residente, fuertes movimientos migratorios estacionales (Gaudemar, 1977). Además la dificultad para acceder a una vivienda a pesar de la gran oferta ociosa $^{60}$ debido a la competencia turística.

El sector hotelero presentó baja rentabilidad, debido al desvío del grueso de la demanda hacia alojamientos en "residencias secundarias"61.

Las ciudades turísticas se presentaron muy estratificadas ${ }^{62-63}$, destacándose diferencias entre los usos, actividades, tipos de construcción, altura de edificios, infraestructura de balnearios, entre otras (Dadon, 1999). Tal como puede observarse en la Figura 2, en 1980 la categoría “departamento" representó alrededor del 30\% de las viviendas particulares ocupadas en los municipios urbanos de La costa, Pinamar y Villa Gesell, durante las décadas siguientes esta proporción disminuyó -encontrándose igualmente significativamente por arriba de la media de la provincia-.

El ferrocarril irá perdiendo importancia frente a transporte automotor público y privado, unido a la expansión de la red vial, permitiendo nuevos modos de hacer turismo (turismo itinerante, miniturismo, camping, etc). Tal como puede observarse en la Figura 2, Las casas de mayor solidez ("tipo A"64) en el hacia 1980 en La Costa, Pinamar y Villa Gesell representaban una proporción inferior al total de la provincia de Buenos Aires, en los años censales siguientes esta situación comienza a converger. 


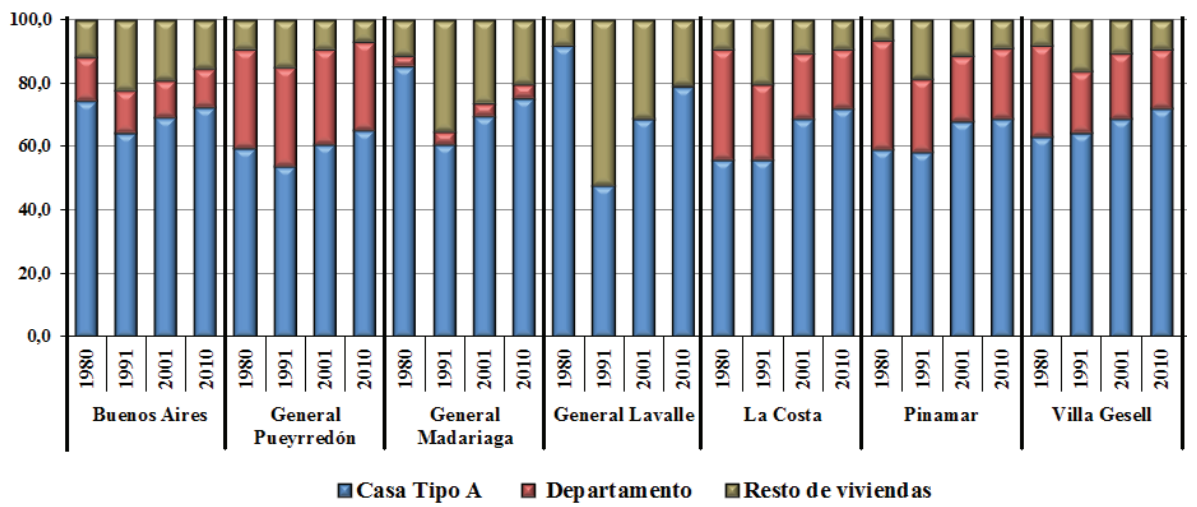

Figura 2 - Viviendas particulares habitadas por tipo de vivienda. Partidos de la provincia de Buenos Aires. Años: 1980,1991, 2001 y 2010.

Notas: "Resto de viviendas" (incluye a las viviendas precarias - ranchos, casillas, piezas en inquilinato, locales no construidos para habitación y viviendas móviles-, y las "casas tipo B" - aquellas que cumplen al menos una de las siguientes condiciones: tienen piso de tierra, no tienen provisión de agua por cañería dentro de la vivienda, o no disponen de baño con descarga de agua-). Las "casas tipo A" corresponden a todas las casas no consideradas tipo B (INDEC, 2012).

Fuente: Elaboración personal sobre la base de información del Instituto Nacional de Estadísticas y Censos. Años 1991, 2001 y 2010.

La densidad de la mancha urbana se destacó por ser muy baja durante los primeros años, y entre 1958 y 1980 las áreas centrales se densificaron incorporando sectores de intensidad de ocupación mínima (Bertoncello, 1989). En 1983 el porcentaje de lotes edificados era muy bajo, llegando a sólo el 21\%, mientras simultáneamente se densificó la ocupación por subdivisión en propiedad horizontal, en un proceso aparentemente paradójico, dado el alto número de lotes vacíos. En el año 1980 la densidad de La Costa113,5hab./Km², Pinamar 84,5y Villa Gesell 40,8, mientras que la de Buenos Aires era de 35,3 hab./ $\mathrm{Km}^{2}-$ en General Madariaga y General Lavalle de tan solo 5,2 y 0,5, respectivamente-. Ver Figura 3. 


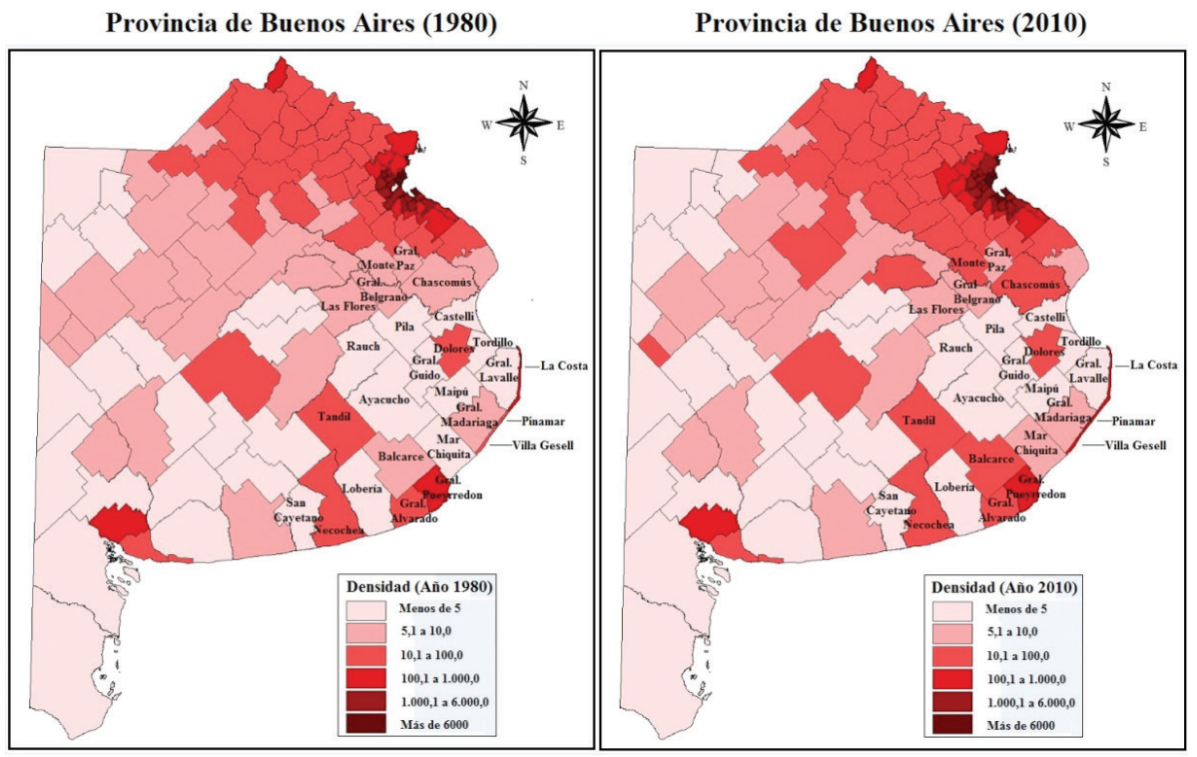

Figura 3.- Densidad (habitantes $/ \mathrm{Km}^{2}$ ). Partidos de la provincia de Buenos Aires. Años: 1980 y 2010.

Fuente: Elaboración personal sobre la base de los censos de 1980 y 2010.

El total nacional y el interior de la Provincia de Buenos Aires presentaron su mayor crecimiento durante el intervalo 1980-1991. En el caso de los partidos costeros el mayor crecimiento se verificó durante el intervalo 1991-2001 (INDEC, 2012).

Según un informe de la OECE ${ }^{65}$, Mar del Plata era el principal centro receptor del país, (OECEI, 1973, p. 608), pero desde aproximadamente 1980 el conjunto de Balnearios del sector norte de la costa atlántica provincial supero a Mar del Plata en el volumen total de turistas.

Los partidos de La Costa, Pinamar y Villa Gesell fueron los de mayor crecimiento poblacional durante el periodo 1991-2001, con variación porcentual relativa muy superior a los restantes (50-100\%). Esto implicó una fuerte urbanización de la zona costera, en la década del noventa se sumaron los proyectos de los modelos de barrios privados. En las décadas siguientes se estancó el crecimiento debido a la crisis económica de la Argentina de fines de los años noventa. La situación se revierte a partir del año 2003, alcanzado intensidad mayor a la que había alcanzado en el 
pasado $^{66-67}$.Hacia el año 2010 La Costa, Pinamar y Villa Gesell presentan aumentos de la densidad 135,8\%, 288,0\% y 108,8\%, en relación al año 1980, respectivamente (Ver Figura 3), mientras que el total de Buenos Aires solo creció tan solo 43,8\%. La singularidad de la revalorización costera fue privilegiar determinados sectores de la trama urbana, recurriendo a productos inmobiliarios vinculados a la lógica de las demandas, generando nuevas funciones en espacios tradicionales (Carvalho; Guzman, 2011). Esta dinámica de la selectividad territorial, se rige por la especulación inmobiliaria, presentando como resultante una alta fragmentación del espacio (Fittipaldi; Mira; Espasa; Facchini, 2015).

\section{Consideraciones finales}

El análisis del desarrollo de los balnearios más populares de la costa atlántica bonaerense en la actualidad, se remonta a la época colonial. Por entonces los pueblos fueron generados por un objetivo netamente de estrategia de defensa, y se adjudicaron bajo divergentes figuras legales de manera de garantizar su ocupación, sin ningún tipo de intervenciones municipales.

Hasta fines del siglo XIX, la franja del territorio costero marítimo bonaerense no era considerado un suelo urbanizable, lejos de eso, ni siquiera atractivo para los agricultores y ganaderos.

Bajo la racionalidad económica de la clase gobernante, el área de análisis, correspondiente a las playas ubicadas al fondo de las estancias, era visualizada como las zonas improductivas del país. Siendo el modelo de urbanización de la época el relacionado con la producción primaria o la existencia de un puerto, ligados a la actividad agropecuaria en el marco de la Argentina agroexportadora

Tras los periodos de derrumbe de la industria saladeril y de crisis agropecuarias, la aparición de una singular “cultura de la playa”, avanzará con el tiempo en la transición urbana de gran parte del territorio de estos partidos, basado en el modelo de Mar del Plata, como caso testigo de la transformación de un paraje ausente en los mapas, convertido en uno de los proyectos de modernización más completos y ricos del sistema urbano argentino en esta época. Pero el éxito de Mar del Plata como villa balnearia también propició la emulación de la especulación inmobiliaria. Se busca valorizar estas tierras mediante la instalación de Balnearios. Este tipo de 
asentamiento urbano se realizó mediante meros trámites administrativos a través de "fundaciones", destacándose grandes desfases entre la traza "real" y la "legal", situación agravada por la topografía, cuya superficie estaba conformada por dunas irregulares y móviles.

Internacionalmente, a mediados del siglo XX la actividad turística se propone como un derecho reconocido para los trabajadores. En el marco del primer gobierno peronista se impulsó la masividad del turismo, de manera que este hábito alcanzará capas cada vez más amplias de la población.

Ante el impulso del turismo interno, durante la década del setenta se da un marcado crecimiento de los núcleos urbanos de la costa bonaerense. Se da un crecimiento inusitadode las viviendas en los municipios urbanos de La Costa, Pinamar y Villa Gesell. La actividad económica queda sujeta a un desarrollo estacional (dos o tres meses por año), imponiendo a la población residente largos periodos de desempleo y dificultades para acceder a la propiedad de una vivienda, ante la fuerte demanda por la viviendas secundarias dedicadas al turismo. Esta característica del mercado desplazóal sector hotelero como principal lugar de alojamiento turístico, y generó un ritmo acelerado de crecimiento basado en el negocio de las residencias secundarias. Al mismo tiempo las ciudades se van estratificando de acuerdo a las diferencias en el tipo de construcción, altura de los edificios y distancia a la costa, entre otras.

\section{Notas}

1 Para describir mostrar las principales características de este proceso hasta mediados del siglo XX, suele recurrirse a la periodización propuestas por diferentes autores (Giberti 1961; Ferrer 1973; Rofman; Romero 1997), que distinguen básicamente cinco etapas: altoperuana; "argentina criolla"; agroexportadora; sustitución de exportaciones; y liberalización y apertura económica.

$2 \mathrm{El}$ actual noroeste argentino comprende las provincias de Jujuy, Salta, Catamarca, La Rioja, Tucumán y Santiago del Estero. La provincia de Córdoba formo parte de la antigua jurisdicción del Tucumán, si bien actualmente no pertenece al NOA (Giovannetti, 2005).

3 El resto del país se encontraba en un estado pre-mercantil, la región del Litoral, subordinada a Buenos Aires se hallaba escasamente poblada, dedicada a actividades ganaderas de subsistencia.

4 Como muestra de la precariedad del sistema urbano, cabe señalar que de las veintinueve ciudades fundadas en el siglo XVI, cinco sufrieron numerosos traslados $\mathrm{y}$ quince desaparecieron (Velázquez y Gómez Lende, 2014). 
5 Las Leyes de Indias representaban normas muy rigurosas sobre la forma de las calles, edificios públicos, distribución de las distintas actividades, etcétera. Sin embargo tras dos siglos que tardo en agotarse el metal, la ciudad de Potosí presento formas tan confusas como las grandes ciudades actuales (Brailovsky; Foguelman, 1993).

6 La penetración española no estuvo exenta de cruentas agresiones a la población nativa (Silveira, 2003; Brailovsky y Foguelman, 1993), además más de la mitad de la población murió, luego del primer contacto con hombres blancos (Ribeiro, 1969). Las riquezas de los yacimientos resultaban productivas a causa de una mínima remuneración y mediante el complejo "trabajo-dieta-epidemia" (Mellafe, 1964), que establecía condiciones inhumanas (Kriedte, 1982).

7 Argentina ingresa en el sistema económico internacional como proveedor de productos agropecuarios y consumidor de manufacturas, que luego se apalanco tras la Gran Inmigración, que adquiere mayor relevancia a partir de 1880 (de Lattes y Lattes, 1975).

8 Los mayores beneficios de la cría de animales, malogró las posibilidades de la agricultura - actividad esencialmente pobladora -, en el contexto en que solo una minoría de hacendados poseedores de títulos de tierra -, para los cuales eran necesarios tener influencia en las esferas oficiales -,hacían valer su posición en contra del desarrollo agrícola (Raimundo, 1981).

9 Los países en proceso de industrialización, Inglaterra en primer término. Generan una creciente demanda de materias primas para elaborar y de alimentos a bajo precio para los trabajadores de las fábricas. Se buscaron mercados para la colocación de productos manufacturados y para la inversión de capitales (Raimundo, 1981). Los intereses de las oligarquías porteñas se articularon con los capitales británicos. Dicho vínculo se fortalecía debido a la hegemonía comercial y portuaria de Buenos Aires, y la alta concentración de la tenencia de la tierra en esta área (Cárcano, 1972).

10 Las sucesivas campañas contra los nativos, los conflictos del avance de las racionalidades liberales británicas y las remanentes racionalidades monopólicas ibéricas y las guerras civiles liberadas entre la provincia de Buenos Aires y el interior del país, constituyeron las variables dominantes del periodo de la "Argentina Criolla".

11 El error de la colonización española se ha condenado las generaciones actuales a la inmovilidad y al atraso, viene de la manera de distribuir las tierras (Sarmiento, viajes, en Raimundo, 1981).

12 En 1737 se presentó en el Cabildo de Buenos Aires, el pedido de la construcción de un fuerte en el pago de arrecifes (Nespolo, 2006), prontamente se sumaron la demanda de construcciones de fuertes en otras zonas como ser Salto, Laguna Brava y La Matanza (Pagden, 1986).

13 La corona española estableció en 1776 el Virreinato del Río de la Plata, su capital era la ciudad de Buenos Aires, de escasa importancia hasta ese momento (Kossok, 1959).

14 La intención era extender el orden municipal en América, avanzando en la fundación de pueblos de labradores que mantuvieran la cuadricula, con un patrimonio administrado por los cabildos (Barcos, 2013). En discrepancia, los terrenos de la provincia de Buenos Aires se otorgaron al margen cualquier normativas específicas (Gelman, 1998; Barba, 1974; Raimundo, 2981). 
15 La triunfante Revolución de Mayo en 1810, se destacó por el adelantamiento de la independencia de los argentinos del poder español antes que otros territorios en América (Kossok, 1959).

16 En el periodo independiente, durante las presidencias de Martín Rodríguez y de Bernardino Rivadavia, se prohibió la venta de tierras públicas, y se implementó el sistema de enfiteusis, con el objetivo de impulsar la labranza. Sin embargo, en el curso de cincuenta años, el Estado veía como un pequeño grupo de hombres, se convirtieron en dueños de descomunales extensiones de tierra ocupada (Oddone, 1967).

17 El "proyecto de Mayo", tenía entre sus objetivos: destruir el monopolio, liberar el comercio exterior y crear un mercado interno capaz - para liberarse del exclusivismo exportador - (Raimundo, 1981).

18 Decreto del 4-IX-1812: "Siendo la población el principio de la industria y el fundamento de los estados.., publica: Art 1*: El Gobierno ofrece protección a los individuos de todas las naciones que quieren fijar su domicilio en el territorio... Art 2*: A los extranjeros que se dediquen al cultivo de los campos se les dará terreno suficiente y se les auxiliara y gozaran de los mismos privilegios que los naturales del país" (Raimundo, p. 63-64, 1981).

19 Su poder se afirmó en la pertenencia a la clase de terratenientes latifundistas, en su gestión se restauró el viejo orden colonial y feudal del cual era heredero. Sus objetivos eran promover el comercio con los ingleses, y mantener el predominio de Buenos Aires. Respecto a las premisas de la Revolución de mayo de 1810 solamente quedo en pie la independencia de España.

20 Ambos partidos tenían en común imponer la hegemonía porteña a las demás provincias - diferencian en los medios, para los unitarios lo adecuado era la constitución, mientras que los federales confiaban en las alianzas -. En la identidad cultural se presentaban mayores diferencias, los unitarios - los "doctores" de la ciudad -, se identificaban con las ideas europeas, en el lado "federal" se representaban en la figura del caudillo, utilizaban el carisma para persuadir a las amplias masas populares en contra de la élite unitaria.

21 Luego de un fallido golpe de Estado por parte de los unitarios y de elecciones que tuvieron que ser anuladas.

22 Hacia 1834 se produce un conflicto - conocido como "Revolución de los Restauradores" -, además se produce el asesinato del exponente del federalismo argentino Facundo de Quiroga - con quien Rosas mantenían una relación de alianzas muy estrechas -, surge una situación de gran incertidumbre política.

23 Tenía por objetivo restringir las importaciones, para favorecer el desarrollo manufacturero de las provincias del interior - representaba un cambio respecto a la ultraliberal política de comercio exterior -. Sin embargo, ley no tendrá dichos efectos, debido a que el gobierno rosista iría mitigando sus estipulaciones.

24 Previamente, en 1836 se dictó una ley que permitió hacerse propietarios de tierras a los hacendados que hasta entonces arrendaban en enfiteusis.

25 Tras una conspiración sufrida en 1838, por parte de los franceses, en conexión con los estancieros de zona sur - autodenominados los "libres del sud" -. Rosas dicta un decreto que concede las tierras expropiada a los unitarios a aquellos que habían participado de su lado en la contienda. Como consecuencia, aumento la concentración de las tierras en manos de los grandes latifundistas - que nunca colonizaron ni cumplieron en lo más 
mínimo las obligaciones que las leyes imponían -. La provincia hacia 1940 era feudo de pocas familias (Raimundo, 1981).

26 Odonne afirma que la tierra publica fue entregada a la marchanta bajo tres formas, por venta o remate; como premio; y con el propósito de colonizar y llevar población a las nuevas líneas de fronteras (Oddone,1967).

27 Los grandes propietarios imponían altos arrendamientos y se negaban a vender sus campos" (Cárcano y Lobos, 1972). A su vez, muchos arrendatarios subarrendaron las tierras y con menos de lo que percibían se hicieron luego propietarios. De esta manera, la tierra más fértil del país quedo en poco propietarios, que debido al aumento de su precio producto de la especulación, desalentaba toda tentativa de adquisición con fines de explotación agrícola (Raimundo, 1981).

28 El combate en la Vuelta de Obligado, finalizó con Inglaterra en 1849 (tratado AranaSouthern) y con Francia algo más tarde, en 1850 (tratado Arana-Leprèdour).

29 Urquiza (encarnando la alianza entrerriano-correntina), representando a la oposición de las provincias del Litoral, lanzo un pronunciamiento en contra Rosas, quien será vencido definitivamente el 3 de febrero de 1852 en la batalla de Caseros.

30 El despilfarro iniciado por Rosas, sigue después de Caseros en idéntica carrera. El deliberado propósito de enriquecer a unos cuantos privilegiados a costa del sudor de los demás. Una ley del 10-I-1867, dio cuenta como la historia de treinta años atrás volvía a repetirse. Oddone comprobó que los derechos de propiedad de los mayores terrateniente de la Provincia en 1836 arrancaba de las "compras" de 1832 y 1867 (Oddone,1967).

31 La ley consideraba como lugares para aumentar la población a las adyacencias de caminos, vías férreas, centros de población mayores o excepcionalmente puertos. El dominio teórico de la ley estuvo al margen de las situaciones preexistentes, no se logró convertir a los pobladores en pequeños propietarios, ni mejoro arrendatarios, por el contrario, pudieron aprovechar el reparto sin tasa de la tierra publica los que ya tenían patrimonio, hasta principios del siglo XX. La desamortización se trató en realidad de un mecanismo para hacer frente a la deuda pública.

32 En 1838 el gobierno francés mandó bloquear el puerto de Buenos Aires como represalia a Rosas que había fusilado servidores de la corona francesa. Al pasar por el Cabo San Antonio los barcos entraban a la Ría y llegaban hasta el puerto, donde se descargaban los artículos alimenticios y de almacén (Varela, 1997).

33 Se realizaban procesos de macerar, secar, salar la carne - que en tiempos de las vaquerías se desperdiciaba -, para luego enviar en barricas a mercados que tenían un poder consumidor muy bajo. Se trataba de todos modos de un rubro exportador, que empleaba hasta varios miles de personas en diversas tareas.

34 Juan Manuel de Rosas en el año 1839 divide el Partido de Monsalvo (creado en 1825), en cuatro partidos: El Tuyú, Mar Chiquita, Rincón de Ajó y Vecino. Con la caída de Rosas las estancias fueron confiscadas y adjudicadas a nuevos propietarios, y todas poseían una porción de playa.

35 En disputa se encontraba un sitio propuesto cerca de la costa, y otro en el interior del Partido más cerca de Maipú (previamente denominado Monsalvo con una población de 3.373 según el censo del año 1865, trocando el nombre por Maipú el 26 de septiembre de 1878). 
36 Hasta el año 1910 denominado partido de Tuyu. La sección Tuyú del Censo de 1869, tiene su origen en la denominación dada por guaraníes evangelizados que acompañaban una expedición organizada por Hernando Arias de Saavedra en el año 1580, su significado era "lodo" o "barro blanco".

37 En 1881 General Lavalle toma el estatus de partido, incorporando en su interior al Partido Rincón de Ajó.

38 En 1879 apareció un barco, Le Frigorifique, que producía frío artificial, transportó a Europa algunas toneladas de carne de oveja congelada. Se perdió una parte, porque se rompió una sección de la maquinaria, pero el resto llegó a Francia en buen estado y fue consumido.

39 Se utiliza la función geométrica para calcular el ritmo de crecimiento poblacional observado entre dos momentos. Su fórmula de cálculo es la siguiente: $r z=[t v(P f / P 1)-1]$ * 1000, siendo rz: tasa de crecimiento medio anual del ano z por cada 1.000 habitantes, y $\mathrm{t}$ : tiempo transcurrido entre la población inicial y la población final (medido en años y fracciones correspondientes).

40 El trigo, maíz, avena, cebada, papa y lino constituyeron los principales cultivos. Todos, a excepción del trigo que descendió hasta desaparecer, ganaron superficie entre 1985 y 1937. En el partido de General Lavalle el maíz pasó de 90 a 2.300 ha y el lino de ninguna a 1.900 ha. En General Madariaga, por su parte, el incremento de superficie cultivada fue aún más notorio. El maíz pasó de 380 a 5.000 ha, la avena de ninguna a 3.500 ha y el lino de ninguna a 3.800 ha (Randle, 1981).

41 En 1874 se autorizó el pedido de licencia del estanciero Peralta Ramos para formación de un pueblo en sus propias tierras.

42 En sus comienzos coexistió otra idea, luego malograda, que era crear una ciudadpuerto, pero no contaba con el apoyo del Estado central ni de la élite dominante argentina.

43 La actividad balnearia nace de las experiencias de la clase alta en los balnearios europeos y norteamericanos para atraer la atención de la clase alta, y convertir un pueblo de campaña recóndito y desconocido del sudeste de la provincia de Buenos Aires ligado a la actividad agropecuaria, en una elegante villa balnearia de la alta sociedad porteña (Groussac, 1904).

44 En agosto de 1888 partía desde Buenos Aires el Gran Ferrocarril del Sud con destino a un pueblo de campaña desconocido del sudeste de la provincia de Buenos Aires ligado a la actividad agropecuaria. Viajaban allí el vicepresidente, el gobernador de la provincia y personalidades con apellidos distinguidos.

45 El progreso de Mar del Plata era una cuestión de política de Estado para la Generación del Ochenta (Dadon, 2005). Se trataba del último proyecto modernista (Cova, 1980), después de la ciudad de La Plata.

46 Uno de los factores es la consolidación de una clase social de altos ingresos y con tiempo libre, que se abocó a una vida dispendiosa en viajes (Schluter, 1985).

47 Hasta ese momento sólo los familiares aprovechaban el ecosistema. Valeria Guerrero, fundadora de Valeria del Mar, relataba: “... hasta ese momento sólo mi primo aprovechaba nuestras playas [...] Nos pedía permiso para llevar allí sus casillas y se pasaba a la orilla del mar todo el verano [...]" (Guerrero, 1970, p. 45). 
48 En este contexto, los pobladores solicitaban a los terratenientes que hicieran arreglos en los caminos para llegar hasta el mar a descansar, refrescarse y pasear (Villar, 2003).

49 Surgió una nueva forma urbana particular en el sistema urbano argentino, hasta el entonces prevaleciente modelo de urbanización, la "ciudad pampeana" (Mantobani, 1997; Ordoqui; Hernández, 2009).

50 Ordoqui y Hernández (2009), lo denomina etapa de Turismo Exclusivo, al periodo que se extiende desde fines del siglo XIX hasta la década de 1930, fundados para el turismo de sol y playa.

51 Al respecto expresa Regina Schluter (1985, p. 4-5), “...se impone la necesidad de contar con una ciudad balnearia alejada de una Buenos Aires atestada de inmigrantes y que permitiese una actividad social intensa".

52 El frente marítimo se encontraba en el fondo de las estancias apropiadas durante los primeros años de la conquista; como se ha mencionado (Buenos Aires, 1941, t.1, v.2).

53 Los Balnearios se desarrollaron con diversas vicisitudes, la modalidad típica implementada fue la aprobación de un plano de subdivisión de un "pueblo" completo. Por ejemplo, la familia Cobo fundo en 1935 el balneario de Mar de Ajó; Juan Carlos Chiozza formó una sociedad en 1939, de la que surgirán las fundaciones de Mar de Ajó Norte y de San Bernardo; se autorizó el balneario Mar del Tuyúa Elias en 1945 en un terreno reservado para el Ferrocarril del Sur férrea; Freidenberg recibió en 1946 la aprobación de los planos del proyecto de Santa Teresita.

54 El principal problema en la realización en el terreno (replanteo), era el topográfico, debido a su superficie estaba conformada por dunas irregulares y móviles, que requerían otras medidas, las cuales nunca se implementaron, dificultando el trazado plano de cuadriculas.

55 Esto fue posibilitado por la sanción de la legislación laboral, que brindo la disponibilidad de tiempo libre, limito la duración de la jornada laboral, y otorgo el derecho a un período de descanso anual pago. De esta manera el turismo entre las clases sociales más desposeídas devino en una necesidad, tanto los sindicatos como la Fundación Eva Perón tuvieron un rol fundamental (Lundberg, 1981; Papson, 1980).

56 Los balnearios del sector costero bonaerense septentrional localizados sobre el cordón medanoso, sr fundaron en las décadas del treinta y cuarenta, y tuvieron un crecimiento acelerado recién a partir de los años sesenta.

57 La Organización Mundial del Turismo considera que el turismo “... es un medio de acceso al derecho de vacaciones y al descanso derivado del derecho al trabajo (OMT, 1980 , s.p.).

58 El acelerado de crecimiento urbano requiero la instrumentación de un régimen especial. Así surgieron los municipios urbanos - que alcanzaran el estatus de Partido durante los ochenta -, La Costa (se desligo de General Lavalle), Pinamar y Villa Gesell (surgió de la división de General Madariaga).

59 El crecimiento de estas localidades presento como contracara, numerosas problemáticas, tales como: deterioro del medio natural y del paisaje; sobreutilización del espacio (particularmente en las calles cercanas a la playa); alto porcentaje de lotes baldíos y construcciones de mala calidad; deficiente provisión de infraestructura y de servicios urbanos -especialmente durante la temporada turística. 
60 En 1980 el municipio urbano de La Costa presentó 82,2\% de viviendas desocupadas, y los municipios de Pinamar y Villa Gesell, $82,6 \%$ y $77,7 \%$, respectivamente.

61 Ofrecieron a los propietarios la posibilidad de obtener una renta, así como las ganancias del permanente aumento del valor de los inmuebles.

62 La provisión de infraestructura y servicios realizada fue la menor posible con el fin de disminuir costos, así mismo ninguna legislación especial se ocupó de las urbanizaciones turísticas (Bertoncello, 1992).

63 Un estudio sobre San Clemente del Tuyú, que puede extrapolarse al resto de los Balnearios, expresa: "carece de todo tipo de planificación urbana [...]. Los departamentos construidos para ser alquilaos o vendidos presentan baja calidad [...] (Edisal, 1971, p. 95).

64 Las "casas tipo A" y los "departamento", son consideradas viviendas de aceptable calidad, mientras que las "casas tipo B" y el "Resto de viviendas" que agrupa las categorías restantes, se supone poseen un grado de precariedad que disminuye las posibilidades de bienestar (INDEC, 2012).

65 Basado en la Encuesta Nacional de Turismo relevada en 1970/71. En segundo lugar se encontraba Córdoba, luego seguían en importancia el Delta, otros centros de Buenos Aires, Mendoza y San Carlos de Bariloche.

66 Las inversiones privadas cobraron mayor dinamismo tras el aumento de la movilidad internacional del capital de las últimas décadas (Chesnais, 1994; Palazuelos, 1998; Mattos, 2007).

67 Estos procesos presentan rasgos comunes en la urbanización de los bordes costeros en la región iberoamericana, como el peso mayoritario de las segundas residencias (Hidalgo Dattwyler et al., 2014).

\section{Referencias}

ARELLANO, S. G.; VILLENEUVE, P. Transformaciones en el espacio sociorresidencial de Monterrey, 1990-2000. Estudios Demográficos y Urbanos, p. 143-178, 2007.

AVELLANEDA, J. B. Estudio sobre las leyes de tierras públicas. Buenos Aires: Ed. La Facultad, 1915.

BARBA, F. Notas sobre las tierras de Patagones y Río Negro. In: Academia Nacional de la Historia, Segundo Congreso de Historia Argentina y Regional, 2003. p. 319-327. (Vol. 1).

BARCOS, M. F. Pueblos y ejidos de la campaña bonaerense: una historia sociojurídica de los derechos de propiedad y la conformación de un partido: Mercedes, 1780-1870. Prohistoria Ediciones, 2013.

BERTOLOTTI, M. I.; GIL DE MURO, J. F. La provincia de Buenos Aires y su participación en el sector pesquero Argentino. Frente Marítimo, 8(sec. B), p. 119125, 1991. 
BERTONCELLO, R. Turismo, medio ambiente y organización del espació. La "Atlántida Argentina" (provincia de Buenos Aires). Buenos Aires: CONICET, 1989 (informe final, mimeo).

BERTONCELLO, R. Configuración socio espacial de los balnearios del Partido de la Costa. Serie monográfica. Buenos Aires, 1992.

BANZATO, G. La herencia colonial: Moderada composición y remates en Buenos Aires, 1780-1822, 2009.

BRAILOVSKY, A. E..; FOGUELMAN D. Memoria Verde. Buenos Aires: Editorial Sudamericana, 1993.

BUENOS AIRES, Archivo Histórico. IV Estudios sobre la historia y la geografía histórica de la provincia de Buenos Aires. La Plata: Taller de Impresiones Oficiales, 1941.

CANEDO, M. Fortines y pueblos en Buenos Aires del siglo XVIII: ¿ Una política de urbanización para la frontera?. Mundo agrario, v. 7, n. 13, 2006.

CÁRCANO, M. Á.; LOBOS, E. Evolución histórica del régimen de la tierra pública, 1810-1916. Buenos Aires: Editorial Universitaria de Buenos Aires, 1979.

CARVALHO, K. D.; GUZMÁN, S. J. M. El turismo en la dinámica territorial ¿Lógica global, desarrollo local?. Estudios y perspectivas en turismo, v. 20, n. 2, p. 441-461, 2011.

CELEMÍN, J. P. Asociación espacial entre fragmentación socioeconómica y ambiental en la ciudad de Mar del Plata, Argentina. EURE (Santiago), v. 38, n. 113, p. 33-51, 2012.

CHESNAIS, F. La mondialisation du capital. Paris : Syros, 1994.

COVA, R. Mar del Plata. Las antiguas ramblas de la playa Bristol. Revista de Arquitectura Nacional Argentina, 1980.

DADON, J. R. Gestión de sistemas con baja biodiversidad: Las playas arenosas del Noreste de la Provincia de Buenos Aires. En: MATTEUCCI, S. D.; SOLBRIG, O. T.; MORELLO, J.; HALFFTER, G. (Ed.). Biodiversidad y uso de la tierra. Conceptos y ejemplos de Latinoamérica. Buenos Aires: CEA, EUDEBA, 1999. p. 529-548.

DADON, J. R. Playas y balnearios de calidad: gestión turística y ambiental: directrices y guía de autoevaluación. Secretaría de Turismo, Secretaría de ambiente y desarrollo sustentable de la Nación, 2005.

DE MATTOS, C. Globalización, negocios inmobiliarios y transformación urbana. Nueva Sociedad, n. 212, p. 82-96, 2007.

EDISAL (Universidad del Salvador) y Consejo Federal de Inversiones. 1971. Diagnóstico de la estructura de la oferta y la demanda turística de la provincia de Buenos Aires. Buenos Aires, mimeo.

FITTIPALDI, R. Á.; MIRA, S. G.; ESPASA, L. C.; FACCHINI, M. E. Aspectos socio-territoriales del fenómeno migratorio en Monte Hermoso. Párrafos Geográficos, v. 14, n. 1, p. 1-22, 2015. 
GAUDEMAR, J.-P. de. Mobilidade do trabalho e acumulagáo do capital. Lisboa: Estampa, 1977.

GELMAN, J.; SCHROEDER, M. I. Juan Manuel de Rosas contra los estancieros: Los embargos a los "unitarios" de la campaña de Buenos Aires. Hispanic American Historical Review, v. 83, n. 3, p. 487-520, 2003.

GHERSA, C.; LEÓN, R. Ecología del paisaje Pampeano: consideraciones para su manejo y conservación. En: NAVEH, Z.; LIEBERMAN, A. S. (Ed.). Ecología de paisajes: teoría y aplicación. Buenos Aires: Editorial Facultad de Agronomía, UBA, 2001. $51 \mathrm{p}$.

GIOVANNETTI, M. La conquista del noroeste argentino y los cultivos europeos. Fronteras de la Historia, 2005.

GROUSSAC, P. El viaje intelectual: impresiones de naturaleza y arte. Madrid: V. Suárez, 1904.

GUERRERO, V. Surge Pinamar. Ed. Del autor: Pinamar, 1970. 43 p.

HIDALGO DATTWYLER, R.; SANTANA RIVAS, D.; VILLAGRÁN CERDA, C. La producción inmobiliaria de segunda residencia en el borde costero del área metropolitana de Valparaíso (1992-2012): tipologías morfológicas en la comuna de Puchuncaví. AUS (Valdivia), v.16, p. 52-58. 2014.

HORA, R. La elite económica Argentina, 1810-1914. Revista de Sociologia e Política, v. 22, n. 52, p. 27-46, 2014.

INDEC. Censo nacional de poblacion, hogares y viviendas 2010: censo del Bicentenario: resultados definitivos. Buenos Aires: Instituto Nacional de Estadistica y Censos, 2012.

INFESTA, M. E.; VALENCIA, M. E. Tierras, premios y donaciones. Buenos Aires, 1830-1860. Anuario IEHS: Instituto de Estudios histórico sociales, v. 2, p. 177-213, 1987.

KOSSOK, M. El Virreynato del Rio de la Plata. Buenos Aires: Futuro, 1959.

LATTES, Z. L. R. de; LATTES, A. E. La población de Argentina. República Argentina, Ministerio de Economía, Secretaría de Estado de Programación y Coordinación Económica, Instituto Nacional de Estadística y Censos, 1975. (Vol. 1).

LUNDBERG, D. E. El negocio del turismo. México: Diana, 1981.

KRIEDTE, P. Die stadt im prozess der europaeischen proto-industrialisierung. Die alte stadt, v.1, 19-51, 1982.

MANTOBANI, J. Notas sobre el problema de la creación de los primeros balnearios argentinos a fines del siglo XIX. Scripta Nova. Revista Electrónica de Geografía y Ciencias Sociales, n. 11, dic.1997.

MELLAFE, R. La esclavitud en Hispanoamérica. Buenos Aires: Editorial Universitaria de Buenos Aires, 1964.

MORELLO, J. Ecología, preferencias turísticas y ambientes extraurbanos. En: CLACSO (Ed.). Medio ambiente y turismo. Buenos Aires: CLACSO, 1983. p.55-72. 
MORENO, J. L.; MATEO, J. El’ redescubrimiento ‘de la demografía histórica en la historia económica y social. Anuario IEHS, v. 12, p. 35-55, 1997.

OECEI. Oficina de Estudios para la Colaboracion Economica Internacional. Argentina económica y social. Buenos Aires, 1973.

NÉSPOLO, E. A. La "Frontera" Bonaerense en el siglo XVIII un espacio políticamente concertado: fuertes, vecinos, milicias y autoridades civilesmilitares. Mundo agrario, v. 7, n. 13, p. 0-0, 2006.

ODDONE, J. La burguesía terrateniente argentina. Buenos Aires: Ediciones Populares Argentinas, 1967.

ORDOQUI, J.; HERNÁNDEZ, F. Caracterización socioterritorial de los asentamientos turísticos-balnearios del litoral marítimo de la Provincia de Buenos Aires. Revista Universitaria de Geografía, v. 18, n. 1, p. 105-140, 2009.

ORGANIZACION MUNDIAL DEL TURISMO. Actas de la Conferencia Mundial de Turismo de Manila. Madrid: OMT, 1980.

PAGDEN, A. La caída del hombre natural: el indio americano y los orígenes de la etnología comparativa. Madrid: Alianza, 1986.

PALAZUELOS, E. La globalización financiera: la internacionalización del capital financiero a finales del siglo XX. Madrid: Editorial Síntesis, 1998.

PAPSON, S. El turismo: una industria ilimitada. Washington: Perspectivas Económicas, 1980. p. 34-39.

PISANI, M. Sector vivienda: estudio preliminar, informe nacional sobre desarrollo humano sostenible. Working Paper. Tegucigalpa: International Organization for Migrations, 1997.

RAIMUNDO, B. Argentina 2000, una nación semidesierta. Buenos Aires: Ediciones Lihuel, 1981.

RANDLE, P. Atlas de desarrollo territorial de la Argentina. Serie de Estadísticas Históricas. Buenos Aires, OIKOS, 1981. p. 44-100.

ROFMAN, A.; L. ROMERO Sistema socioeconómico y estructura regional en la Argentina. Buenos Aires: Amorrortu Editores, 1997.

SANTOS, M. La naturaleza del espacio: técnica y tiempo; razón y emoción. Barcelona: Ariel Geografía, 2000. 348 p.

SILVEIRA, M. L. Finanças, consumo e circuitos da economia urbana na cidade de São Paulo, Caderno CRH, Salvador, v. 22, n. 55, p. 65-76, jan./abr. 2009.

SILVEIRA, M. Historia para arqueólogos. La cadena alimenticia del vacuno: época colonial y siglo XIX y su relación con el uso del espacio en la ciudad de Buenos Aires. Buenos Aires: Instituto de Arte Americano en Investigaciones Estéticas, 2003.

SCHLUTER, R. Turismo y parques nacionales. Buenos Aires: CIET, 1983.

SCHLUTER, R. Turismo y áreas protegidas en Argentina. Buenos Aires: CIET, 1985.

VARELA, J. La región del Tuyú: apuntes de cátedra. Inédito. Mar del Tuyú, 1997. $178 \mathrm{p}$. 
VELÁZQUEZ, G. A.; GOMEZ LENDE, S. Metropolización y Desmetropolización: tendencias y cambios en el sistema urbano argentino (2001-2010), 2014.

VERÓN, E. El partido de la Costa: un análisis histórico de sus principales problemáticas socioeconómicas y ambientales. In: ACTAS XX JORNADAS DE HISTORIA ECONÓMICA. Mar del Plata: Asociación Argentina de Historia Económica, 2006. p. 1-19.

VERÓN, E. M.; BARRAGÁN MUÑOZ, J. M. Transformación y funcionalización del Socioecosistema Litoral Norte de la provincia de Buenos Aires, Argentina. Revista Universitaria de Geografía, v. 24, n. 2, p. 91-117, 2015.

VERVOORST, F. La vegetación de la República Argentina VII. Las comunidades vegetales de la Depresión del Salado. Buenos Aires: INTA 7, 1967. p. 7-72. (Serie Fitogeográfica).

VILLAR, M. C. Espacio, mito y representaciones sociales. Algunos ingredientes y un desarrollo por el litoral marítimo argentino. Rev. Reflexiones Geográficas, 2003, 20 pp.

contribuição dos autores

Os autores trabalharam juntos na determinação e justificativa da seleção do tema, objetivos específicos, estruturação e redação, bem como na revisão de todas as seções. Fernando Ariel Manzano foi responsável pela pesquisa de dados, edição e descrição de tabelas e figuras

Guillermo Ángel Velázquez encarregou-se da investigação dos dados históricos sobre o tema e da preparação da configuração dos fatores históricos, ambientais, sociais e econômicos, que se apresentam em todos os setores, e que estão ligados à formação específica dos assentamentos. da costa atlântica de Buenos Aires.

Ambos desenvolvemos a fusão de todas as entradas e os dados de contexto na introdução, conclusão e parágrafos resumidos.

Fernando Ariel Manzano - Licenciado en Economía por la Universidad de Buenos Aires. Licenciado en Sociología por la Universidad de Buenos Aires. Doctor en Demografía por la Universidad Nacional de Córdoba. ORCID: https://orcid.org/0000-0002- 1513-4891

Guillermo Ángel Velázquez - Doctor en Filosofía y Letras (Geografía), por la Universidad de Buenos Aires. Investigador Superior del CONICET. ORCID: http://orcid.org/0000-0003-0892-6572 